\title{
Neuroprotective Functions of Alpinia galanga in Forebrain Ischemia Induced Neuronal Damage and Oxidative Insults in Rat Hippocampus
}

\author{
Ravi Mundugaru*1,2 Senthilkumar Sivanesan1, Padmaja Udaykumar ${ }^{3}$, Vidyadhara D J4, \\ Suchitra Narayan Prabhu ${ }^{5}$, Basavaiah Ravishankar ${ }^{6}$
}

${ }^{1}$ Department of Research and Development, Saveetha Institute of Medical and Technical Sciences, Chennai, Tamilnadu, INDIA. 2Department of Pharmacology, Kodagu Institute of Medical Sciences, Madikeri, Karnataka 571 201, INDIA.

${ }^{3}$ Department of Pharmacology, Father Muller Medical College, Mangalore, Karnataka, INDIA.

${ }^{4}$ Department of Neurophysiology, National Institute of Mental Health and Neurosciences (NIMHANS), Hosur road, Bangalore- 560029, Karnataka, INDIA

${ }^{5}$ Department of Pharmacognosy and Phytochemistry, SDM Centre for Research in Ayurveda and Allied Sciences, Udupi, Karnataka, INDIA.

${ }^{6}$ Department of Pharmacology and Toxicology Laboratory, SDM Centre for research in Ayurveda and Allied Sciences, Kuthpady, Udupi, Karnataka, INDIA.

\begin{abstract}
Introduction: The rhizomes of Alpinia galanga (L.) Willd (Zingiberaceae) commonly known as greater galangal, a ginger substitute for food and was traditionally used as nervine tonic and stimulant. The present study was designed to screen the neuroprotective role of hydroalcoholic extract of rhizome of Alpinia galanga (HAAG) in transient forebrain ischemia induced neuronal damage and oxidative injury in the rat brain. Materials and Method: The transient forebrain ischemia was induced by bilateral common carotid artery occlusion in anesthetized rats for $60 \mathrm{~min}$, followed by reperfusion injury. The transient forebrain ischemia induced neuronal damage and oxidative stress was assessed by estimating the percentage survival neurons in the Cornu ammonis CA 1 and CA3 regions of hippocampus, MDA levels and antioxidant enzymes activities in the brain homogenate. Open field, actophotometer and grip strength tests were used for behavioral assessment. Recovery in spontaneous motor activity in actophotometer test and number of squares crossed and rearing behavior in the open field test are indicators of cognitive enhancement after treatment with Alpinia galanga. Results and Discussion: Treatment with Alpinia galanga attenuated the delayed neuronal death in the CA1 and CA3 regions of hippocampus. Reduced post-ischemic brain tissue MDA levels at both the drug doses and increased antioxidant enzyme such as glutathione peroxidase at a higher dose was also noted, which indicates Alpinia galanga is neuroprotective against ischemic hippocampal injury. The present study demonstrated that treatment with HAAG attenuated forebrain ischemic reperfusion induced neuronal injury and oxidative stress in hippocampus. Conclusion: Treatment with Alpinia galanga may have the potential to be used as a protective agent in forebrain ischemic injury.
\end{abstract}

Key words: Transient forebrain ischemia, Cornu ammonis, Oxidative stress, Alpinia galanga (L.) Willd., lipid peroxidation, Actophotometer test.

\section{INTRODUCTION}

Ischemic stroke makes the nerve cells deprived of oxygen and glucose, which results in temporary or permanent damage in the ischemic areas of the brain, leading to various functional disabilities. ${ }^{1}$ Several works have demonstrated that a forebrain ischemia attack induces selective delayed death in hippocampal Cornu ammonis 1 (CA1) pyramidal neurons, especially after 3-7 days of ischemic attack in rats and gerbils. $^{2-5}$ The mechanisms contributing to the selective and delayed hippocampal
Submission Date: 28-02-2018; Revision Date: 13-04-2018; Accepted Date: 17-04-2018

DOI: 10.5530/ijper.52.4s.79 Correspondence: Ravi Mundugaru, Department of Pharmacology, Kodagu institute of Medical Sciences, Madikeri, Karnataka, INDIA. Phone: + 919986118401 E-mail: ravisdm13@gmail. com

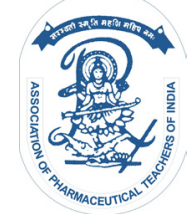

www.ijper.org 
neuronal deathin differentanimal models of cerebralischemia have implicated several factors such as increase inglutamate activity, intracellular calcium, increased generation of reactive oxygen species (ROS) such as superoxide anion $\left(\mathrm{O}_{2}-\right)$, hydroxyl radical $\left(\mathrm{OH}^{-}\right), \mathrm{H}_{2} \mathrm{O}_{2}$ and $\mathrm{NO}^{6,7}$ The ROS are directly involved in the oxidative damage of cellular macromolecules such as lipids, proteins and nucleic acids in the ischemic tissues. It can trigger the generation of pro-inflammatory cytokines, which leads to the inflammatory and degenerative changes in the ischemic brain tissues. ${ }^{8}$

In transient forebrain ischemia, the neuronal injury occurs around the ischemic core, called the penumbra, which continuously develop over several hours. The neuronal tissues within the penumbra will lose the property of normal neuronal functions such as conduction or generation of electrical impulses but it is viable and considered to represent salvageable tissue that can be targeted with different neuroprotective interventions. ${ }^{9}$ The slow development of ischemic damage within the penumbra provides a window of opportunity for neuroprotective therapies. Attenuating and/or delaying this time-dependent brain injury may improve neurological outcome and facilitate brain recovery from injury. ${ }^{10}$ There are wide range of experimental models that have been used to confer the protection to the ischemic insults or to the penumbra that includes scavenging reactive oxygen species (ROS), inhibitors of synthesis and release of excitotoxic neurotransmitters, suppressors of neuronal metabolism, anti inflammatory agents and membrane stabilizers. ${ }^{11}$

Alpinia galanga (L.) Willd., (Family - Zingiberaceae), commonly called as Greater galangal is a medicinal herb that is widely used in Indian systems of medicine for the treatment of diabetes, arthritis, inflammatory disorders, dementia and neurodegenerative diseases. ${ }^{12,13}$ The extract of rhizome of this herb has been reported to possess pharmacological activities such as anti-inflammatory, analgesic, anti-diabetic, anticancer, anti-melanogenic, anti-fungal, antibacterial, antioxidant, anti-apoptosis, antileishmanial, antidementia, hepatoprotective and CNS stimulant activity. ${ }^{14-23}$ It is one of the important rasayana (rejuvenator) herb used in classical formulations for the management of chronic disease conditions. ${ }^{24}$ Galangoisoflavanoids, $\beta$-sitosterol diglucosyl caprate, methyleuginol acetoxycineoles, galangal acetate, transp-coumaric acid, galanganol $\mathrm{B}$ and 4-dimethoxycinnamyl alcohol are the known bioactive components of A. galanga. The phenolic compounds, such as acetoxychavicol acetate and hydroxychavicol acetate have shown potent anti-oxidant and anti-inflammatory activities. ${ }^{25-31}$ The aqueous and ethanolic extracts of rhizome of A. galanga have potent antioxidant capacity. It inhibits lipid peroxidation in pancreas, liver and brain homogenates of diabetic rats. ${ }^{16}$ It lowers lipid peroxidation by maintaining the activities of endogenous antioxidant enzymes such as superoxide dismutase, catalase and other antioxidants such as glutathione at higher levels in $A \beta_{25-35}$ induced amnesia in mice and it could reduce oxidative stress induced progression of neurodegenerative disorders such as Alzheimer's disease. ${ }^{32-33}$ Several authors demonstrated that aqueous and alcoholic extract of rhizome part of the plant is a powerful scavenger of ROS against 1,1 diphenyl-2-picrylhydrazyl radical. ${ }^{34}$ Additionally, several studies have shown that the extracts of rhizome of $A$. galanga can exhibit remarkable anti-inflammatory and analgesic effects. ${ }^{15}$ It inhibits acetylcholine esterase enzymes and reduces cognitive impairments and dementia. ${ }^{35}$ Thus several of these pharmacological activities appear to be beneficial in cerebral ischemia.

In this study, we investigated the possible protective effect of hydroalcoholic extract of rhizome of A. galanga [HAAG] against transient forebrain ischemia induced neuronal damage in the CA1 and CA3 regions of hippocampus. Fourteen days of reperfusion after in vivo forebrain ischemia was carried out in Wistar rats, following which behavioral, histological and oxidative stress-related biochemical parameters were studied under different treatment conditions.

\section{MATERIALS AND METHODS}

\section{Plant material and extract preparation}

The rhizomes of $A$. galanga were procured from Calicut, Kerala, India and authenticated in Pharmacognosy laboratory at Sri Dharmasthala Manjunatheshwara Centre for Research in Ayurveda and Allied Sciences, Udupi, India. The voucher specimen no. 17032303 was deposited for future reference. The rhizome was shade dried and pulverized at SDM Pharmacy, Udupi. The hyrdoalcoholic extract of $A$. galanga was prepared by soaking $500 \mathrm{~g}$ of powdered rhizome of $A$. galanga in 2 liters of $50 \%$ ethanol in distilled water at room temperature for $24 \mathrm{~h}$, filtered and concentrated by evaporating on water bath till free from solvents.

\section{Animals}

Male Wistar albino rats weighing 200 to 250 g body weight were obtained from Central Animal Facility at SDM centre for Research in Ayurveda and Allied Sciences, Udupi, India. The animals were maintained at standard laboratory conditions such as temperature at $25-27^{\circ} \mathrm{C}$, humidity of 50 to $55 \%$ and natural light and 
dark cycles. Animals were fed with commercial pellet diet (Pranav agro Industry, Pune) and water ad libitum. Prior to the experimentation, approval was obtained from Institutional Animal Ethical Committee (Reference no. SDMCRA/IAEC/PH-01/22/08/ 2014-15).

\section{Experimental protocol}

The transient forebrain ischemia was induced by bilateral common carotid artery occlusion (BCCAO) followed by reperfusion injury. The rats were randomly divided into four groups ( $\mathrm{n}=12$ in each group). Vehicle control rats were administered with $0.5 \%$ carboxyl methyl cellulose orally and subjected to sham operated ischemia. BCCAO group administered with $0.5 \%$ carboxyl methyl cellulose served as ischemic control. An acute toxicity study performed based on OECD test guidelines has reported that Alpinia galanga has $\mathrm{LD}_{50}>2000 \mathrm{mg} / \mathrm{kg}$ body weight and hence 200 and $400 \mathrm{mg} / \mathrm{kg}$ body weight was chosen as dose for the current study. ${ }^{36}$ BCCAO HAAG $200 \mathrm{mg} / \mathrm{kg}$ group was administered with 200 $\mathrm{mg} / \mathrm{kg}$ body weight of HAAG for 14 consecutive days (p.o) after transient forebrain ischemia. Similarly, a higher dose of $400 \mathrm{mg} / \mathrm{kg}$ body weight of HAAG was administered in BCCAO - HAAG $400 \mathrm{mg} / \mathrm{kg}$ group for 14 consecutive days (p.o), after transient forebrain ischemia.

\section{Surgical procedure to induce transient forebrain ischemia}

The rats were anaesthetized using Ketamine $(80 \mathrm{mg} / \mathrm{kg})$ and xylazine $(3 \mathrm{mg} / \mathrm{kg})$ combination by intra peritoneal route of administration. The ventral region of neck was sterilized using $70 \%$ alcohol before surgery. A midline incision was made and soft tissues were pulled apart and both common carotid arteries were exposed and separated from vagus nerve. The cerebral ischemia was induced by simultaneous occlusion of both common carotid arteries for $60 \mathrm{~min}$, followed by acute ischemic reperfusion injury caused by untying the temporary ligature and releasing the thread. The incision was sutured with 2.0 silk sutures. The body temperature was maintained at $37^{\circ} \mathrm{C}$ by controlled heating lamp throughout the period of ischemia and recovery from anesthesia. ${ }^{37-38}$

\section{Behavioral testing}

\section{Open field test}

The open field behaviors such as number of rearing, number of fecal pellets expelled, number of squares crossed, duration of immobility (freezing time) and the time of initiation was done according to protocol described by Bhattacharya and Satyan, 1997. ${ }^{39}$ The open field test was conducted on $14^{\text {th }}$ day after transient forebrain ischemia.

\section{Actophotometer test (Locomotor activity)}

Locomotor activity was assessed by using digital actophotometer. The motor activities were recorded for a period of 5 min by means of photocells and counters activated by the movement of rat across the light beam inside the actophotometer chamber. ${ }^{40}$ Locomotor assessment was made in all the groups on $14^{\text {th }}$ day of ischemia.

\section{Grip strength test}

Grip strength was assessed by using digital grip strength meter. The rats were lifted by their tail to the height where the front paws were at the same height as the bar. Rats were then moved horizontally towards the bar until it became within reach. Visually checked to see the grip strength was good i.e. symmetric, tight grip with both fore limbs and exerting a detectable resistance against the investigators pull. Rat was gently pulled away until its grasp was broken. The pulling was at a constant speed and sufficiently slow to permit the rat to build up the resistance against it. The transducer was set to record the peak value and the procedure was repeated 3 times to obtain the best performance. ${ }^{41}$

\section{Preparation of brain tissue homogenate}

Brain was excised and cleaned with ice cold saline and stored at $-20^{\circ} \mathrm{C}$. Shorty before conducting the biochemical estimation, brain tissues were thawed and homogenized in phosphate buffer saline of $\mathrm{pH} 7.4$, centrifuged at $4^{0} \mathrm{C}$ and the supernatant collected was subjected to assessment of various biochemical parameters. Excess supernatant of the brain tissue homogenate was stored at $-20^{\circ} \mathrm{C}$ for any further use.

\section{Determination of catalase activity}

The brain tissue homogenate $(1 \mathrm{~mL})$ was mixed with $5 \mathrm{~mL}$ of phosphate buffer $\mathrm{pH} 7.4$ and $4 \mathrm{~mL}$ of $0.2 \mathrm{M} \mathrm{H}_{2} \mathrm{O}_{2}$ in phosphate buffer and time was noted. Exactly $180 \mathrm{sec}$ after adding $\mathrm{H}_{2} \mathrm{O}_{2}$, a set of $1 \mathrm{~mL}$ of reaction mixture from the above was taken in $2 \mathrm{~mL}$ dichromate acetic acid. It was kept in boiling water bath for $10 \mathrm{~min}$, cooled all the tubes under running tap water and finally noted the reading at $570 \mathrm{~nm}$ against reagent blank. Catalase activity in the tissue was expressed as micromoles of $\mathrm{H}_{2} \mathrm{O}_{2}$ consumed $/ \mathrm{mg}$ protein $/ \mathrm{min}^{42}$

\section{Determination of lipid peroxidation}


Lipid peroxidation activity was determined by measuring the content of the thio-barbituric acid reactive substances (TBARS) using UV-Visible double beam spectrophotometer (Systronics 2201). The level of lipid peroxidation was expressed as milli moles of malondialdehyde (MDA) formed per gram wet tissue. ${ }^{43}$

\section{Determination of glutathione peroxidase}

Glutathione peroxidase was estimated using a standard protocol, and the glutathione peroxidase activity was expressed as micro molar glutathione utilized per $\mathrm{mg}$ protein per min at $37^{\circ} \mathrm{C} .{ }^{44}$

\section{Histopathology of brain}

Cresyl violet (CV) staining was performed (to analyze the degree of neuronal survival in the CA1 and CA3 regions of hippocampus).

At the end of behavioral studies, the rats were euthanized by sodium pentobarbitone $(100 \mathrm{mg} / \mathrm{kg}$ body weight, intra peritonial). The brains were carefully dissected out, fixed in 10\% formalin and processed for paraffin embedding. Six brain samples from each group were used and ten slices per sample were examined for histopathalogical study. The coronal sections were cut at $8 \mu \mathrm{m}$ thickness using rotary microtome (Leica RM 2155, Germany). The sections were stained with cresyl violet as per standard procedure. ${ }^{45}$ All slides were then evaluated under light microscope (ZEISS Axio lab A1, India).

\section{Quantification of surviving neurons of CA1 and CA3 region}

Quantitative analysis of cresyl violet stained cells was carried out by a person who was blind to the group of animals. The neurons in the control group and the surviving neurons from all the treatment groups in the CA1 and CA3 regions were quantified in $1 \mathrm{~mm}^{2}$ area focused using Axio cam ERc 5s (ZEISS) software. The total number of normal neuronal cell bodies (with normal cell membrane, nucleus and not darkly stained) were counted manually.

\section{RESULTS}

\section{Effect of HAAG drug in transient forebrain ischemia induced oxidative stress in rat brain}

Lipid peroxidation in BCCAO control group was significantly increased after ischemic reperfusion injury than the vehicle control (Figure 1A, BCCAO Vs Vehicle, @@ $p<0.01$ ), thereby indicating oxidative degradation of lipids. Both low and high dose HAPL drug treatment to post ischemic rats attenuated this oxidative stress response, and revealed statistical significance (Figure 1A, BCCAO, ${ }^{\#} p<0.01 \mathrm{Vs}$ BCCAO + HAAG $200 \mathrm{mg} / \mathrm{kg}$,
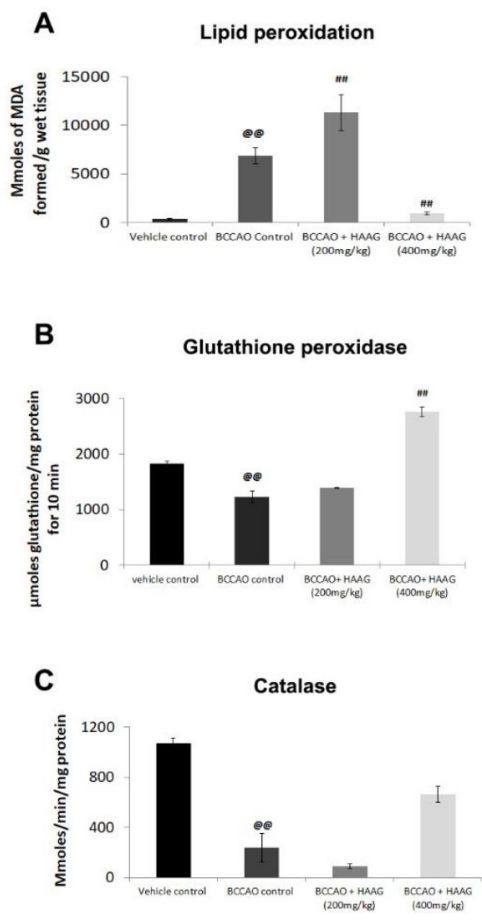

Figure 1: Biochemical investigations showing the assessment of (A) lipid peroxidation (B) glutathione peroxidase and $(\mathrm{C})$ catalase levels in vehicle control, BCCAO control and BCCAO +HAAG drug $(200 \mathrm{mg} / \mathrm{kg}$ and $400 \mathrm{mg} / \mathrm{kg})$ treatment groups.

$\# \#<0.01 \mathrm{Vs}$ BCCAO + HAPL $400 \mathrm{mg} / \mathrm{kg}$ ). Similarly, BCCAO followed by reperfusion injury caused marked oxidative stress that led to decrease in the antioxidant enzyme activities such as glutathione peroxidase (Figure 1B, BCCAO Vs Vehicle, ${ }^{\circledR} p<0.01$ ) and catalase (Figure 1C, BCCAO Vs Vehicle, $\left.{ }^{\circledR @} p<0.01\right)$. HAAG drug administration, both at low and high doses considerably recovered the ischemic injury induced alterations of glutathione peroxidase levels, however the high dose significantly recovered the glutathione peroxidase as compared to ischemic control (Figure 1B, BCCAO, $\# p<0.01 \mathrm{Vs}$ BCCAO + HAAG $400 \mathrm{mg} / \mathrm{kg}$ ). Catalase activity was not improved in HAAG groups (Figure 1C).

\section{Ameliorative effect of HAAG on locomotor defects in transient forebrain ischemia}

Transient forebrain ischemia revealed highly significant reduction in total locomotion counts as compared to vehicle control (Figure 2G, BCCAO control Vs Vehicle

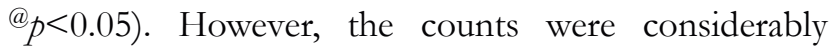
increased in both doses of HAAG. But lower dose of HAAG group revealed better locomotion with significant increase in the number of counts as compared to ischemic 
injury group (Figure 2E, F and G, BCCAO + HAAG $200 \mathrm{mg} / \mathrm{kg}$ Vs BCCAO control, $\left.{ }^{*} p<0.05\right)$.

Transient forebrain ischemia induced deficits in open field exploratory behaviors were ameliorated after HAAG treatment

Transient forebrain ischemia caused significant reduction in the total number of squares crossed by the rats (Figure 2 A, BCCAO Vs Vehicle, ${ }^{\circledR}{ }_{p}<0.01$ ) and considerable decrease in the rearing and grooming behavior and number of fecal pellet expelled in the open field test as compared to vehicle control. Though rearing and grooming behaviors were found to be affected by ischemic reperfusion injury, it was not significant (Figure 1C and D, ET-1 Vs vehicle). Treatment with both low and high doses of HAAG considerably increased the total number of squares crossed, however HAAG at $400 \mathrm{mg} / \mathrm{kg}$ showed significance (Figure 1A, BCCAO, @ $p<0.05 \mathrm{Vs}$ BCCAO + HAAG $400 \mathrm{mg} / \mathrm{kg}$ ). Rearing behavior was also significantly increased at higher doses of HAAG (Figure 1B, BCCAO, \#\#p<0.01 Vs BCCAO + HAAG $400 \mathrm{mg} / \mathrm{kg}$ ). Recovery in grooming behavior was noted only in lower dose of HAAG group; however it was not significant as compared to BCCAO control.

\section{Effect of HAAG on grip strength after transient forebrain ischemia}

There was significant decrease in the grip strength of ischemic control group rats as compared to vehicle control (Figure 2H, BCCAO Vs Vehicle, $@ @_{p<0.01)}$. Treatment with both low and high doses of HAAG considerably increased the grip strength. However, HAAG at $400 \mathrm{mg} / \mathrm{kg}$ group significantly improved as compared to ischemic control (Figure 2H, BCCAO, $\# \# p<0.01 \mathrm{Vs}$ BCCAO + HAAG $400 \mathrm{mg} / \mathrm{kg}$ ).

\section{Effect of HAAG drug treatment on percentage survival of pyramidal cells of CA1 and CA3 regions of hippocampus in the transient forebrain ischemia}

Microscopic qualitative examination of CA1 and CA3 regions of hippocampus within vehicle control group under high magnification revealed compactly arranged healthy pyramidal cells with nucleus, and intact cell membrane (Figure 3, A and E). The BCCAO control group of rats showed darkly stained, irregular shrunken pyramidal cells with narrow pyramidal cell layer with ectopic cells and increased pyknotic nuclei (Figure 3, $\mathrm{B}$ and F). The intactness of pyramidal cell layer was maintained and overall recovery in neuronal morphology was evident after HAAG drug treatment, both in CA1 and CA3 subdivisions of hippocampus affected by ischemic reperfusion injury (Figure 3, compare $\mathrm{C}$ and
A

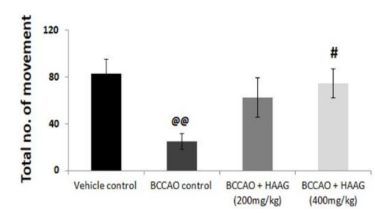

C

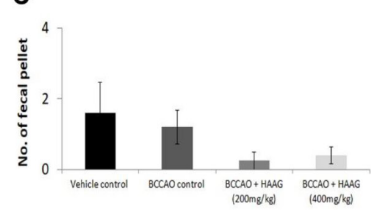

E

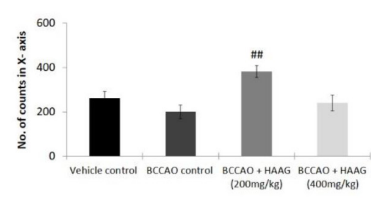

G

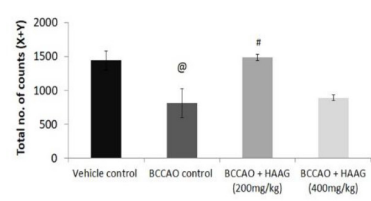

B

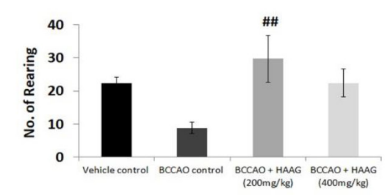

D

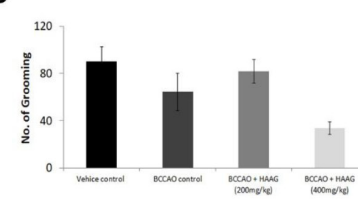

$\mathbf{F}$

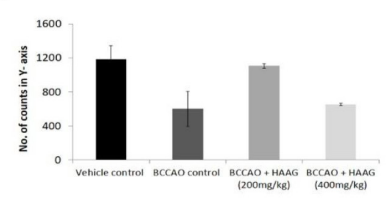

H

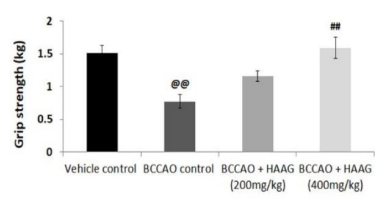

Figure 2: Animal behavioral studies performed by Open field test, Actophotometer test, Grip strength test in vehicle control, BCCAO control and BCCAO +HAAG drug $(200 \mathrm{mg} / \mathrm{kg}$ and $400 \mathrm{mg} / \mathrm{kg}$ ) treatment groups. The assessment of locomotor activity by movement (A), rearing behavior (B), number of fecal pellet expelled (C), grooming behavior (D), total number of squares crossed (E, $F$ and $G$ ), and grip strength $(H)$ are shown respectively.

$\mathrm{D}$ with $\mathrm{B}$, and $\mathrm{G}$ and $\mathrm{H}$ with $\mathrm{F}$ ). The ischemic reperfusion injury significantly reduced the percentage survival of pyramidal neurons in both CA1 and CA3 regions of hippocampal area as compared to vehicle control (Figure 3, CA1, compare B with A, I, BCCAO Vs Vehicle, @@p<0.01; CA3, compare F with E, J, BCCAO Vs Vehicle, $@ @_{p<0.01)}$. High dose of HAAG (400 mg/ $\mathrm{kg}$ ) treatment significantly attenuated the BCCAO induced neuronal loss in hippocampal CA1 region (Figure 3, compare D with B, I, BCCAO, ${ }^{\# \#} p<0.01 \mathrm{Vs}$ BCCAO + HAPL $400 \mathrm{mg} / \mathrm{kg}$ ). HAAG both at low and high doses attenuated the percentage recovery of cells in the CA3 region as compared to BCCAO control group, significantly (Figure 3, compare G, H and F, $\mathrm{J},{ }^{\# \#} p<0.01$, BCCAO Vs BCCAO+ HAAG $200 \mathrm{mg} / \mathrm{kg}$ ${ }^{\#} p<0.05$, BCCAO Vs BCCAO + HAAG $400 \mathrm{mg} / \mathrm{kg}$ ).

\section{DISCUSSION}

The evidence from preclinical and clinical investigations suggests that the global cerebral ischemic subjects have 


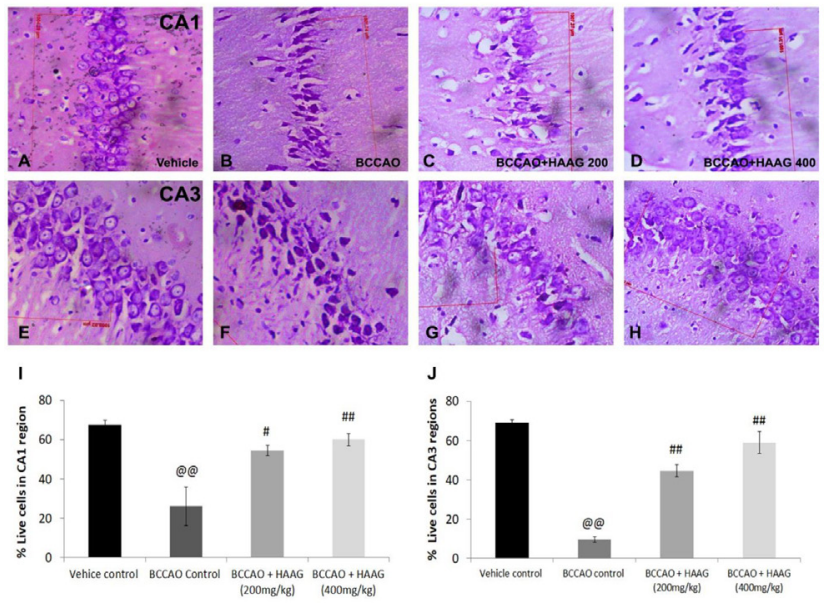

Figure 3: Photomicrograph of representative cresyl violet stained brain sections focused on CA1 and CA3 hippocampal regions of vehicle control (A, E), BCCAO control (B, F) $B C C A O+H A A G 200 \mathrm{mg} / \mathrm{kg}(C, G)$ and BCCAO + HAAG 400 $\mathrm{mg} / \mathrm{kg}(\mathrm{D}, \mathrm{H})$ groups.

shown impaired memory, cognitive dysfunction and pathological damage in different brain regions. ${ }^{46}$ In addition, transient forebrain ischemia is responsible for the induction of hippocampal injury. ${ }^{47-48}$ The data of present study indicated that a $60 \mathrm{~min}$ of forebrain ischemic insult in rat resulted in a massive damage to CA1 and CA3 hippocampal neurons (greater than $60 \%$ of the neurons died) when assessed at $14^{\text {th }}$ day after reperfusion (Figure 3). This degree of cell loss was similar to most published studies in rat and gerbil models of forebrain ischemia. ${ }^{49-55}$

Global cerebral ischemia has been reported to cause marked decrease in the locomotor activity 15 days after global cerebral injury, which has been demonstrated in locomotor activity test. ${ }^{56}$ Consistent with the studies mentioned above, decrease in the locomotor and grip strength was observed in the present study after $60 \mathrm{~min}$ forebrain ischemia. It has been reported that hippocampal damaged rats showed increased locomotor activity after treating with dopamine receptor agonists (D1 and D2) as compared to control rats. It suggests the involvement of dopaminergic mechanism and involvement of hippocampus in the locomotor activities. Interestingly, decreased locomotor activities were significantly attenuated by HAAG drug treatment for 14 consecutive days after ischemic reperfusion injury, which suggests that HAAG drug has therapeutic potential against ischemic reperfusion injury induced impaired locomotor activity. Transient forebrain ischemia caused significant reduction in the total number of squares crossed by the rats and considerable decrease in the rearing and grooming behavior and number of fecal pellet expelled in the open field test as compared to vehicle control. In the present study, treatment with HAAG drug escalated cognitive function in the open field exploratory test with considerable increase in the number of squares crossed and rearing behavior. This supports the promising effect of HAAG in enhancing cognitive behavior.

Results from the present study confirmed that massive tissue damage is directly associated with the induction of oxidative stress. In biological system $\mathrm{O}_{2}{ }^{-}$is inactivated by endogenous superoxide dismutase (SOD), while $\mathrm{H}_{2} \mathrm{O}_{2}$ is decomposed to water by catalase (CAT) and the glutathione peroxidase (GPx) ${ }^{57-58}$ During brain ischemic reperfusion injury, reactive oxygen species (ROS) cannot be readily scavenged because of low activity of SOD, CAT and GSH. In biological systems, lipid peroxidation is found to be an important cause of cell membrane destruction and neuronal death. MDA, one of the major products of lipid peroxidation, has been extensively studied and measured as an index of lipid peroxidation. ${ }^{58-61}$ In the present study forebrain ischemic insult resulted in significant increase in the hippocampal MDA level and considerable depletion of hippocampal glutathione peroxidase and catalase. This suggests the forebrain ischemic reperfusion insult induced overproduction of reactive oxygen species (ROS), which caused hippocampal oxidative stress. The elevated levels of reactive oxygen species (ROS) generated during ischemic reperfusion injury, stimulate cells to secrete inflammatory cytokines and chemokines which subsequently cause the secondary ischemic damage. This is characterized by the infiltration of leucocytes and microglial activation. ${ }^{62-63}$ Therefore, drugs that have a wide spectrum of inhibitory actions on inflammation and oxidative stress may be useful in rescuing neuronal cells exposed to ischemia. In the present study, treatment with HAAG $(400 \mathrm{mg} / \mathrm{kg}$ ) afterischemic reperfusion injury markedly attenuated the declined catalase and glutathione peroxidase activity in the hippocampal tissue; however only HAAG administered at $400 \mathrm{mg} / \mathrm{kg}$ has significantly increased glutathione peroxidase as compared to ischemic control group. The protective effect of HAAG against oxidative stress caused by forebrain ischemia could be assessed by enhancing the cerebral activity of endogenous antioxidant enzymes or by scavenging and preventing ROS generation in brain tissue.

In the present study, rats were treated with HAAG at 200 and $400 \mathrm{mg} / \mathrm{kg}$ immediately after ischemic reperfusion injury and continued for fourteen consecutive days that led to significantly decreased brain MDA levels as compared to ischemic control group. This protection given by HAAG drug may be due to the antioxidant property. From the earlier studies it appears that the ethanolic extract of rhizome of $A$. galanga had shown 
significant antioxidant activity determined by 2, 2 diphenyl-1-picrylhydrazyl (DPPH) and oxygen radical absorbance capacity (ORAC) methods. ${ }^{34}$ In another study, the various fractions of ethanolic extract of rhizome of $A$. galanga showed significant antioxidant activity in $\mathrm{A} \beta . \mathrm{A} \beta_{25-35}$ intoxicated mice brain where the endogenous antioxidant enzymes such as SOD, catalase, glutathione peroxidase and vitamin $\mathrm{C}$ were restored to a significant level. The lipid peroxidation was significantly lowered as compared to $A \beta_{25-35}$ intoxicated control group..$^{32,33}$ Also, similar effect of ethanolic extract of A.galanga against elevated TBARS level and depleted SOD, catalase and glutathione peroxidase in kidney tissue of fructose induced metabolic syndrome in rats was reported elsewhere. ${ }^{64}$

The hippocampus is an important area of brain which regulates memory and cognitive function. It has relatively a poor blood supply and the inhibitory interneurons are in deep intraparenchymal structures and hence they are more susceptible to factors such as hypoxia, ischemia and hypoglycemia. ${ }^{65}$ The microscopic examination of CA1 and CA3 regions of hippocampus under high magnification revealed compactly arranged healthy pyramidal cells with nucleus and intact cell membrane in the vehicle control. The forebrain ischemic control rats showed darkly stained, irregular pyramidal cells with narrow pyramidal cell layer (PCL) with increased pyknotic cells (PC) and ectopic pyramidal cells (EPC). The PCL was intact and percentage live cells were markedly increased in HAAG administered group in a dose dependant manner as compared to ischemic control. This might be due to the antioxidant and ROS scavenging activity of A. galanga, which might thus have a protective role in the ischemic reperfusion, induced oxidative stress.

\section{CONCLUSION}

The behavioral, biochemical and histopathalogical findings of the present study indicate that the rhizome of Alpinia galanga confers neuroprotection against transient forebrain ischemic insult by attenuating neuronal injury and oxidative stress in hippocampal tissues.

\section{ACKNOWLEDGEMENT}

The authors are highly grateful to Research Director and Dean, Saveetha University, Chennai, for their constant motivation to carry out this research work. The authors thank revered President Dr. D. Veerendra Heggade for his constant support, and Dr. B. Ravishankar, Director, SDM Research Centre, Udupi, for their guidance.

\section{FINANCIAL SUPPORT AND SPONSORSHIP}

Nil.

\section{CONFLICT OF INTEREST}

There are no conflicts of interest.

\section{COMPETING INTERESTS}

There are no competing interests in this publication.

\section{FUNDING}

Self-funding.

\section{ABBREVIATIONS}

HAAG: Hydro alcoholic extract of Alpinia galanga; BCCAO: Bilateral common carotid artery occlusion, ROS: reactive oxygen species, CAT: Catalase; GSH-Px: Glutathione peroxidase; SOD: Superoxide dismutase; TBARS: Thio-barbituric acid reactive substances; MDA: Malondialdehyde; CNS: Central nervous system; H2O2: Hydrogen peroxide; CA: Cresyl violet, CA1: Cornu ammonis 1, CA3: Cornu ammonis 3, A $3.25-35$ - Amyloid $\beta$ ANOVA: Analysis of variance; SEM: Standard error of mean; DPPH: 2, 2 diphenyl1-picrylhydrazyl, EPC: Ectopic pyramidal cells, PCL: Pyramidal cell layer, PC: Pyknotic cells, OECD: Organization for Economic Co-operation and Development, ORAC: oxygen radical absor $\neg$ bance capacity.

\section{REFERNCES}

1. Dalley JW, Cardinal RN, Robins TW. Prefrontal executive and cognitive functions in rodents: Neuronal and neurochemical substrates, Neurosci. Biobehav. Rev. 2004;28(7):771-84.

2. Wolfe CD. The impact of stroke. Br Med Bull. 2000;56:275-86.

3. Colbourne $\mathrm{F}, \mathrm{Li} \mathrm{H}$, Buchan AM, Clemens JA. Continuing post ischemic neuronal death in CA1: Influence of ischemia duration and cytoprotective doses of NBQX and SNX-111 in rats. Stroke. 1999;30(3):662-8.

4. Rami A, Agarwal R, Botez G, Winckler J. Mu-Calpain activation, DNA fragmentation, and synergistic effects of caspase and calpain inhibitors in protecting hippocampal neurons from ischemic damage. Brain Res. 2000;866(1-2):299-312.

5. Barber PA, Auer RN, Buchan AM, Sutherland GR. Understanding and managing ischemic stroke. Can J Physiol Pharmacol. 2001;79(3):283-96.

6. Iadecola C, Alexander M. Cerebral ischemia and inflammation. Curr Opin Neurol. 2001;14:89-94.

7. Raivivh G, Jones LL, Werner A, Bluthmann H, Doetschmann T, Kreutzberg GW. Molecular signals for glial activation: Pro and anti-inflammatory cytokines in the injured brain. Review. Acta Neurochir Suppl. 1999;73:21-30.

8. Shah IM, Macrae IM, Di Napoli M. Neuroinflammation and neuroprotective strategies in acute ischemic stroke from bench to bedside. Curr Mol Med. 2009;9(3):336-54

9. Legos JJ, Barone FC. Update on pharmacological strategies for stroke: prevention, acute intervention and regeneration. Curr Opin Investig Drugs. 2003;4(7):847-58.

10. Sacco R, Chong J, Prabhakaran S. Experimental treatments for acute ischaemic stroke. Lancet. 2007;369(9558):331-41. 
11. McDonald ES, Windebank AJ. Mechanisms of neurotoxic injury and cell death. Neurol Clin. 2000;18(3):525-40.

12. Indrayan AK, Agarwal P, Rathi AK, Shatru A, Agrawal NK, Tyagi DK. Nutritive value of some indigenous plant rhizomes resembling Ginger. Nat Prod Rad. 2009;8(5):507-13.

13. Arambewela LS, Arawwawala M, Owen NL, Jarvis B. Volatile oil of Alpinia galanga Wild of Sri Lanka. J Essent Oil Res. 2007;19(5):455-6.

14. Chudiwal AK, Jain DP, Somani RS. Alpinia galanga willd. An overview of phyto-pharmacological properties. Indian Journal of Natural Products and Resources. 2010;1(2):143-9.

15. Subhash KR, Bhanu Prakash G, Vijay Chandra Reddy K, Manjunath K, Umamaheshwara Rao K. Anti inflammatory activity of ethanolic extract of Alpinia galanga in Carrageenan induced pleurisy rats. Natl J Physiol Pharma Pharmacol. 2016;6(5):468-70.

16. Kaushik P, Kaushik D, Yadav J, Pahwa P. Protective Effect of Alpinia galanga in STZ Induced Diabetic Nephropathy. Pakistan Journal of Biological Sciences. 2013;16(16):804-11.

17. Al Yahya MA, Rafathulla S, Mossa JS, Ageel AM, Al Said MS, Tariq M. Gastric Antisecretory, Antiulcer and Cytoprotective Properties of Ethanolic Extract of Alpinia galanga Willd in Rats. Phytotherapy Research. 1990;4(3):112-4.

18. Shih H, Pickwell GV, Quattrochi LC. Differential effects of flavonoids compounds on tumor promoter-induced activation of human CYP1 A2 enhancer. Arch Biochem Biophys. 2000;373(1):287-94.

19. Vinit B, Zanobia S, Jennifer NG, Malari AC, Patrick A, John DiGiovanni, et al. Effects of the tropical ginger compound, 1'-acetoxychavicol acetate, against tumor promotioninK5.Stat3C transgenic mice. Journal of Experimental and Clinical Cancer Research. 2012;31(1):1-14.

20. Saha S, Banerjee S. Central nervous system stimulant actions of Alpinia galanga (L.) rhizome: A preliminary study. Indian Journal of Experimental Biology. 2013;51:828-32.

21. Kaur A, Singh R, Dey CS, Sharma SS, Bhutani KK, Singh IP. Antiliishmanial phenylpropanoids from Alpinia galanga (Linn.) Willd. Indian J Exp Biol. 2010;48(3):314-7.

22. Banjerdpongchai R, Punyati P, Nakrob A, Pompimon W, Kongtawelert P. 4-Hydroxycinnamaldehyde from Alpinia galanga (Linn.) induces human leukemic cell apoptosis via mitochondrial and endoplasmic reticulum stress pathways. Asian Pac J Cancer Prev. 2011;12(3):593-8.

23. Rao K, Ch B, Narasu LM, Giri A. Antibacterial activity of Alpinia galanga (L) Wild crude extracts. Appl Biochm Biotechnol. 2010;162(3):871-84.

24. Srivastava P, Shanker K. Chemical and biological potential of Rasayana herb used in traditional system of medicine. Fitoterapia. 2012;83(8):1371-85.

25. Raffacle C, Nicola M. Inhibitory effect of the plant flavonoid galangin on rat vasdeferens in vitro. Life Sci. 2003;72(26):2993-3001.

26. Janssen AM, Scheffer JJ. Acetoxychavicol acetate, an antifungal component of Alpinia galanga. Planta Med. 1985;51(6):507-11.

27. Cheah PB, Abu Hasim NH. Natural antioxidant extract from galangal (Alpinia galanga) for minced beef. J Agric Food Chem. 2000;80(10):1565-71.

28. Zhu XL, Yang MH, Luo JG, Huang XF, Kong LY. A new phenyl propanoid from Alpinia galangal. Chin J Nat Med. 2009;7(1):19-20.

29. Jaju SB, Indurwade NH, Sakarkar DM, Fuloria NK, Ali MD, Basu SP. Isolation of $\beta$ - sitosterol diglucosyl caprate from Alpinia galanga. Pharmacognosy Res. 2010;2(4):264-66.

30. Havsteen BH. Flavonoids, a class of natural products of high pharmacological potency. Biochem Pharmacol. 1983;32(7):1141-8.

31. Yang X, Eilerman RG. Pungent principle of Alpinia galanga (L.) Swartz and its application. J Agric Food Chem. 1999;47(4):1657-62.

32. Hanish Singh JC, Alagarsamy V, Prakash VD. Sathesh Kumar, Nisha JC, Narsimha Reddy $\mathrm{Y}$. Neuroprotective effect of Alpinia galanga (L.) fractions on $A \beta_{(25-35)}$ induced amnesia in mice. Journal of Ethnopharmacology. 2011;138(1):85-91.

33. Hanish Singh JC, Alagarsamy V, Sathesh Kumar, Narsimha Reddy Y. Neurotransmitter Metabolic Enzymes and Antioxidant Status on Alzheimer's Disease Induced Mice Treated with Alpinia galanga (L.) Willd. Phytotherapy research Phytother Res. 2011;25(7):1061-7.

34. Mahae N, Chaiseri S. Antioxidant activities and antioxidant components in extracts of Alpinia galanga (L.) Sw. Kasetsart J Nat Sci. 2009;43:358-69.
35. Vinutha B, Prashanth D, Salma K, Sreeja SL, Pratiti D, Padmaja R, et al. Screening of selected Indian Medicinal plants for acetylcholinesterase inhibitory activity. J Ethnopharmacology. 2007;109(2):359-63.

36. Subash KR, Muthulakshmi BG, Jagan RN, Binoy VC. Phytochemical screening and acute toxicity study of ethanolic extract of Alpinia galanga in rodents. International Journal of Medical Research and Health Sciences. 2012;2(1)93-100.

37. Smith ML, Bendek G, Dahlgren N, Rosen I, Wieloch T, Siesjo BK. Models for studying long-term recovery following forebrain ischemia in the rat, II: A 2-vessel occlusion model. Acta. Neurol Scand. 1984;69(6):385-401.

38. Fadhel A, Mahmoud NN, Mustafa MA, Khalda SA, Abdulhakeem AAM. Delayed Treatments with Curcumin Prevents Forebrain Ischemia-Induced Neuronal Damage and Oxidative Insult in the Rat Hippocampus. Neurochem Res. 2006;31(5):611-8.

39. Battacharya SK, Satyan KS. Experimental methods for evaluation of psychotropic agents in rodants: I- Antianxiety agents. Indian J Exper Biol. 1997;35(6):565-75.

40. Bansinath M, Bose AC, Hema S, Guruswami MN. Interaction of metamizol with some hypnotic in rats. Arch Int Pharmacodyn Ther. 1977;229:327-36.

41. Smith JP, Hicks PS, Ortiz LR, Martinez MJ, Mandler RN. Quantitative measurement of muscle strength in the mouse. J Neurosci Methods. 1995;62(1-2):15-9.

42. Sinha KA. Colorimetric assay of catalase. Anal Biochem. 1972;47(2):389-94.

43. Ohkawa H, Ohishi N, Yagi K. Assay for lipid peroxides in animal tissues by Thio-barbituric acid reaction. Anal Biochem. 1997;95(2):351-8.

44. Rotruck JT, Pope AL, Ganther HE, Swanson AB, Hafeman DG, et al. Selenium: Biochemical role as a component of glutathione peroxidase. Science. 1973;179(4073):588-90.

45. Bancroft JD, Stevens A. Pigments and minerals. In: Bancroft JD, Stevens A (eds) Theory and practice of histological techniques, $3^{\text {rd }}$ edn. Churchill Livingstone, New York. 1990. p 262.

46. Fisher M, Feuerstein G, Howells DW, Hurn PD, Kent TA, Savitz SI, et al. Update of the stroke therapy academic industry roundtable preclinical recommendations. Stroke. 2009;40(6):2244-50.

47. Candelario-Jalil E, Alvarez D, González-Falcón A, García-Cabrera M, Martínez-Sánchez G, Merino N, et al. Neuroprotective efficacy of nimesulide against hippocampal neuronal damage following transient forebrain ischemia. Eur J Pharmacol. 2002;453(2-3):189-95.

48. Colbourne F, Li H, Buchan AM, Clemens JA. Continuing postischemic neuronal death in CA1: Influence of ischemia duration and cytoprotective doses of NBQX and SNX-111 in rats. Stroke. 1999;30(3):662-8.

49. Liu PK, Grossman RG, Hsu CY, Robertson CS. Ischemic injury and faulty gene transcripts in the brain. Trends Neurosci. 2001;24(10):581-8.

50. Kirino T. Delayed neuronal death in the gerbil hippocampus following ischemia. Brain Res. 1982;239(1):57-69.

51. Knuckey NW, Palm D, Primiano M, Epstein MH, Johanson CE. $\mathrm{N}$-acetylcysteine enhances hippocampal neuronal survival after transient forebrain ischemia in rats. Stroke. 1995;26(2):305-11.

52. Al Nita D, Nita V, Spulber S, Moldovan M, Popa DP, Zagrean AM, et al. Oxidative damage following cerebral ischemia depends on reperfusion-a biochemical study in rat. J Cell Mol Med. 2001;5(2):163-70.

53. Nanri K, Montecot C, Springhetti V, Seylaz J, Pinard E. The selective inhibitor of neuronal nitric oxide synthase, 7-nitroindazole, reduces the delayed neuronal damage due to forebrain ischemia in rats. Stroke. 1998;29(6):1248-54.

54. Chandrasekaran K, Mehrabian Z, Spinnewyn B, Drieuand K, Fiskum G. Neuroprotective effects of bilobalide, a component of the Ginkgo biloba extract (EGb 761), in gerbil global brain ischemia. Brain Res. 2001;922(2):282-92.

55. Shen H, Zhang L, Yuen D, Logan R, Jung BP, Zhang G, et al. Expression and function of $\mathrm{A} 1$ adenosine receptors in the rat hippocampus following transient forebrain ischemia. Neuroscience. 2002;114(3):547-56.

56. Marc RM, Helene P. Time-dependent effects of global cerebral ischemia on anxiety, locomotion, and habituation in rats. Behavioral Brain Research. 2009;200(1):173-80.

57. Asma B, Ranajoy C, Shankar M. Oxidative stress: An essential factor in the pathogenesis of gastrointestinal mucosal disease. Physiological Review. 2014;94(2):329-54.

58. Schrader M, Fahimi HD. Peroxisomes and oxidative stress. Biochim Biophys Acta. 2006;1763(12):1755-66. 
Fuh KC, Meneshian A, Patel CB, Takiar V, Bulkley GB. Signal transduction by reactive oxygen species: Alternative paradigms for signaling specificity. Surgery. 2002;131(6):601-12. with nimesulide reduces oxidative stress following global ischemic brain injury in gerbils. Neurosci Res. 2003;47(2):245-53.

61. Al-Majed AA. Aminoguanidine prevents oxidative stress insult following transient forebrain ischemia in the rat hippocampus. Saudi Pharmaceutic J. 2004;12(4):150-6.
62. Driscoll I, Hong NS, Craig LA, Sutherland RJ, McDonald RJ. Enhanced cell death and learning deficits after a mini-stroke in aged hippocampus. Neurobiology of Aging. 2007;29(12):1847-58.

63. Wang $Q$, Tang XN, Yenari MA. The inflammatory response in stroke. Journal of Neuroimmunology. 2007;184(1):53-68.

64. Allur S, Viswanathan P, Carani V. Anuradha. Dose-dependent effect of galangin on fructose-mediated insulin resistance and oxidative events in rat kidney. Redox Report. 2010;15(5):225-32.

65. Yamaoka Y, Shun Shimohama, Kimura J, Takeshi T. Neuronal damage in the rat hippocampus induced by in vivo hypoxia. Experimental and Toxicologic Pathology. 1993;45(4):205-9.

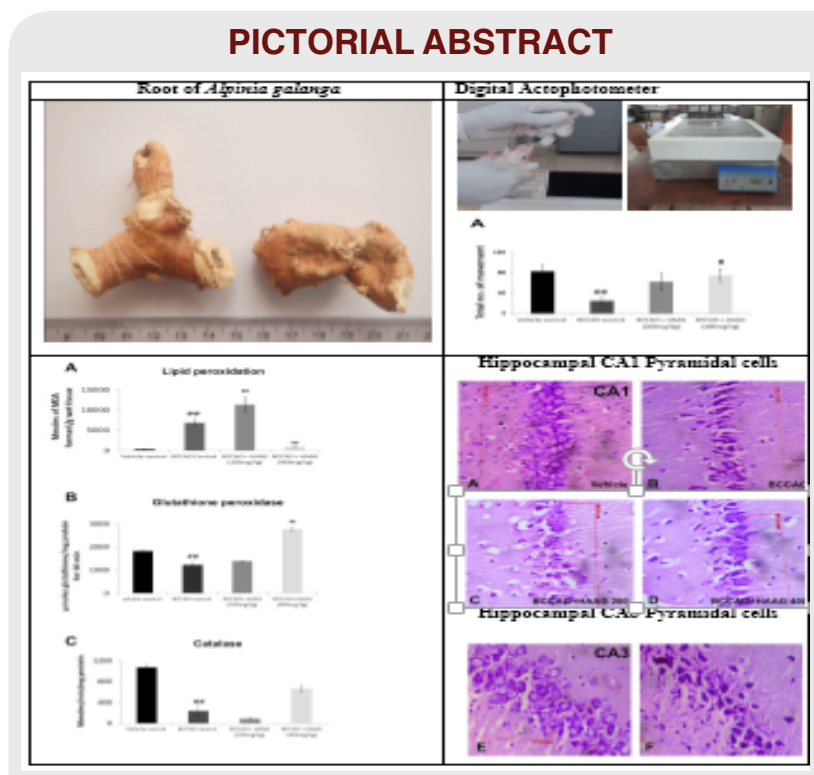

About Authors

\section{SUMMARY}

- The hydro alcoholic extract of rhizome of Alpinia galanga (HAAG) showed neuroprotective activity in albino rats against transient forebrain ischemia induced neuronal damage and oxidative injury in the rat hippocampus.

- The transient forebrain ischemia induced cognitive impairment was significantly attenuated by treatment with Alpinia galanga at higher dose level.

- The benefits of Alpinia galanga against oxidative stress induced by transient forebrain ischemia includes reduced lipid peroxidation and increased anti oxidant enzymes such as catalase and glutathione peroxidase in hippocampal tissue.

- Delayed neuronal death in the CA1 and CA3 regions of hippocampus was significantly attenuated by higher dose of the Alpinia galanga extract.

- Alpinia galanga holds pharmacological potentials for treating pathological consequences of ischemic stroke.

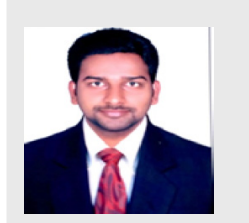

Mr. Ravi Mundugaru is working as Research Officer in Pharmacology \& Toxicology at SDM Ayurveda and Allied Sciences, Udupi, India. He is MSc in Medical Pharmacology from Manipal University, Manipal and persuing PhD from Saveetha University, Chennai. He is investigating AYUSH-EMR projects on safety evaluation of two important Herbo-mineral formulations used in the Ayurvedic practice. His field of expertise includes in vitro and in vivo assays in Pharmacology and Toxicology, cell and molecular biology. He is Author of 40 research papers in national and international peer reviewed journals.

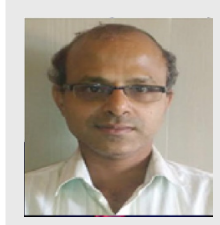

Dr. S. SENTHILKUMAR has obtained Ph.D in Biochemistry/Bioorganic Neurochemistry from University of Madras, Chennai and pursued Postdoctoral research training at E-M-A University of Greifswald, Germany, lowa State University and Stanford University School of Medicine, USA. $\mathrm{He}$ is presently working as Associate Professor in the Department of Research and Development, Saveetha Institute of Medical and Technical Sciences, Chennai, India. His research focuses on the pathogenesis of neurological diseases such as Alzheimer's, Parkinson's and Stroke and developing therapeutics. He has published more than 30 research papers in refereed journals and has been serving as reviewer for many neuroscience related journals. He is a guest editor for the Journal Biochemistry Insights.

Cite this article: Mundugaru R, Sivanesan S, Udaykumar P, Vidyadhara D, Prabhu SN, Ravishakar B. neuroprotective Functions of Alpinia galanga in Forebrain Ischemia Induced Neuronal Damage and Oxidative Insults in Rat Hippocampus. Indian J of Pharmaceutical Education and Research. 2018;52(4S):S77-S85. 